\title{
EVALUATION OF SUSTAINABILITY-ORIENTED TRANSVERSAL COMPETENCIES IN ENGINEERING POSTGRADUATE STUDIES
}

\author{
I.J. Navarro1, A.J. Sánchez-Garrido1, V. Yepes² \\ ${ }^{1}$ Dept. of Construction Engineering, Universitat Politècnica de València (SPAIN) \\ ${ }^{2}$ Institute of Concrete Science and Technology (ICITECH), Universitat Politècnica de \\ València (SPAIN)
}

\begin{abstract}
In recent times, education for sustainability is gaining more and more relevance in the field of engineering. One of the recently established Sustainable Development Goals explicitly calls for the achievement of sustainable infrastructures by 2030. Infrastructures are recognised as a crucial element towards a sustainable future, as they are responsible for a vast amount of environmental damages and economic expenses, but also are considered to be essential to achieve social welfare and the economic development of regions. Sustainable design of infrastructures requires a paradigm shift in the way engineering students are taught how to face design problems. The complex relation that exists between the conflicting dimensions in which sustainability is founded, namely economy, environment and society, requires of future engineers to develop a series of transversal competencies during their postgraduate studies. However, there are no objective criteria on which to base the assessment of the degree of acquisition of these skills.
\end{abstract}

This paper presents an objective methodology for the evaluation of one of the key competencies required for sustainability-oriented future engineers, namely critical thinking. The proposed methodology is based on the evaluation of the coherency expressed by the students when dealing with a sustainability-related design problem. Such consistency shall be mathematically quantified by means of the Analytic Hierarchy Process. Through the resolution of a particular case study, where students are required to complete a survey comparing different sustainability criteria pairwise, the professor is able to obtain a consistency index from the comparison matrices derived from the survey results of each student. Such indicator is a valuable tool to assess both the clarity with which students perceive sustainability as well as their ability to meet the new challenges that the society will face in the near future.

Keywords: Sustainability, critical thinking, analytical hierarchy process, transversal competencies, postgraduate education.

\section{INTRODUCTION}

The United Nations General Assembly adopted in 2015 the Agenda for Sustainable Development, the first-ever signed universal agreement which aims to establish an unprecedented framework to fight against climate change and poverty [1]. This so-called 2030 Agenda is formulated in 17 Sustainable Development Goals (SDG) that should be accomplished by 2030. Such goals, build on the success of the Millenium Development Goals, are focused on addressing the most urgent global problems: protecting the environment and the degradation resulting from climate change, promoting fair and free societies, eradicating hunger and poverty in all its forms, or ensuring a state of prosperity and social welfare, among others. Although not legally binding, countries are expected to establish the required national frameworks for the implementation and achievement of the challenging 17 Goals prior to 2030. Being the universities core research centers for countries, they are to a great extent responsible for the development of the knowledge needed to face the new and ambitious challenges posed by the paradigm shift resulting from the SDGs. On the other hand, universities play also an essential role, insofar as they allow for the adequate education of professionals with the technical capacity to properly solve the complex economic, environmental and social challenges arising from the 2030 Agenda.

However, the adequate education of future professionals shall not be based on the sole provision of the technical knowledge provided by traditional engineering courses [2, 3], but shall also guarantee that the students correctly understand the complexity and the extent of the problem to be solved. To this end, in the context of compliance with the SDG, special emphasis must be placed on the development of transversal competencies in postgraduate studies [4]. Such competencies are 
particularly relevant when it comes to engineering students: In addition to requiring engineering professionals to acquire transversal competencies such as critical thinking, systemic thinking, selfawareness, social responsibility and regulatory skills, the ninth SDG explicitly requires them to be able to design sustainable infrastructures. During the last recent years, the design of sustainable infrastructures has been in the spotlight of many researchers. Studies can be found that deal with the sustainable performance of a variety of infrastructures, such as buildings $[5,6]$, bridges $[7,8]$, or roads [9]. Research on sustainable design of infrastructures does not only focus on the cost optimisation of structural designs [10,11], but also on the environmental $[12,13]$ and the social impacts resulting throughout the life cycle of infrastructures $[14,15]$. However, the university education system still requires a major transformation to ensure the acquisition and evaluation of transversal competencies oriented to this end.

In line with the above, the Vice-Rectorate for Studies, Quality and Accreditation of the Polytechnic University of Valencia (UPV) has recently established a strategic plan for the evaluation and accreditation of the achievement of each of the 13 transversal competencies that shall be provided by the UPV. These transversal competencies (TC) include: Integration and understanding (TC-1), practical thinking (TC-2), problems analysis and resolution (TC-3), innovation, creativity and entrepreneurship (TC-4), design and project (TC-5), teamwork and leadership (TC-6), ethical, environmental and professional responsibility (TC-7), effective communication (TC-8), critical thinking (TC-9), knowledge of contemporary challenges (TC-10), lifelong learning (TC-11), time planning and management (TC-12), and specific instrumentation (TC-13).

Among the proposed set of transversal competencies included in the abovementioned plan, critical thinking (TC-9) is considered to be an essential competency that shall be provided by postgraduate curricula oriented towards sustainable development [16]. One of the key skills resulting from a succesful critical thinking is the judgement consistency [17]. Such coherence is also considered to be a fundamental pillar for the development of other soft skills expected from future professionals aligned with the SDG, namely decision-making, the ability to foresee alternative future scenarios, as well as the ability to identify the complex connections that exist between the environmental, social and economic dimensions of sustainability $[18,19]$.

In spite of the extense and precise definition of the different concepts included in the UPV strategic plan for the accreditation of transversal competencies, the evaluation of competencies is nowadays still a complex and challenging task. This is due to the fact that there is still no consensus as to which capacities make those competencies up and consequently as to which skills should be evaluated [20]. On the other hand, it is also not evident that teachers are able to correctly assess certain competencies. In this sense, some authors recommend having students as evaluators of their own skills or those of their peers [21], although this evaluation approach must not necessarily be exent from an uncertain amount of subjectivity [22]. In view of the above, the present communication proposes an objective tool to evaluate the capacity of students to think critically based on the resolution of a particular case study and the evaluation of the consistency held by the students in their judgements. The Analytic Hierarchy Process (AHP) is proposed here to evaluate the degree of coherency of the students.

\section{METHODOLOGY}

\subsection{Fundamentals of the evaluation procedure}

The Analytic Hierarchy Process (AHP) is a Multi-Criteria Decision Making (MCDM) method developed by Thomas L. Saaty [23]. This method is used to determine the relative importance that each of the criteria or alternatives involved in a particular MCDM problem on the basis of pairwise comparisons. Such comparison shall be based on the so called Saaty's Fundamental Scale, which translates a closed set of 9 semantic values into 9 numeric integers ranging from 1 to 9 . Those semantic values included in the Fundamental Scale express different levels of how much more relevant one criterion or alternative is considered to be with respect to another, being 1 equivalent to the judgement " $A$ and $B$ are equally important", and being 9 equivalent to the judgement " $A$ is extremely more important than $B$ ". The remaining intermediate numeric values between 1 and 9 are meant to express intermediate levels of comparison. So, the experts involved in the decision making process are requested to compare the importance of couples of criteria or alternatives by choosing for each comparison only one of the 9 semantic alternatives. 
By using the Saaty's Fundamental Scale, a square comparison matrix can be constructed. Each element $a_{i j}$ in the matrix corresponds to the numeric value of the judgement emited by each expert when comparing the relevance of criterion/alternative $i$ with criterion/alternative $j$. It shall be noted that this matrix is, by definition, reciprocal. That means that if criterion $A$ is considered to be more important than criterion $B$, then criterion $B$ must be less important than criterion $A$ to the same extent. That means that if $a_{i j}=x$, then $a_{i j}=1 / x$. The method AHP allows to obtain the weight of each criterion/alternative as the values of the eigenvector corresponding to the highest eigenvalue of the comparison matrix.

In order for the resulting weights to be mathematically valid, Saaty's method requires the decision matrix to be consistent, that is, that the judgments that the decision maker has made when constructing the decision matrix are coherent with each other. The evaluation methodology proposed here is based precisely in the way such coherency can be calculated mathematically. AHP establishes a procedure for calculating the Consistency Index $(\mathrm{Cl})$ of the decision matrix as:

$$
C I=\frac{\lambda_{\max }-n}{n-1}
$$

Where $\mathrm{n}$ is the number of criteria/alternatives involved in the decision making problem, and $\lambda_{\max }$ is the greatest eigenvalue of the comparison matrix. From the obtained $\mathrm{Cl}$, a Consistency Ratio $(C R)$ can be obtained by dividing $C l / R I$, where $R I$ is a random index expressing the consistency derived from a completely random copmarison matrix. The values of $R I$ depend on the dimension $n$ of the comparison matrix, and are presented in Table 1:

Table 1. RI values [21].

\begin{tabular}{l|c|c|c|c|c}
\hline \hline Number of criteria $\mathrm{n}$ & 2 & 3 & 5 & 7 & 9 \\
\hline Random Index (RI) & 0 & 0.58 & 1.12 & 1.32 & 1.45 \\
\hline \hline
\end{tabular}

If the result for $\mathrm{Cl}$ of a particular comparison matrix is close to $\mathrm{Rl}$, that means that the matrix has been filled in a completely random way, thus expressing absolute inconsistency and lack of knowledge when assessing the problem to be solved. On the contrary, a low Consistency Ratio indicates that the decision-maker has a clear vision of the problem to be solved. Consequently, it reflects that the decision-maker has a sufficiently developed capacity for critical thinking so as to be able to understand the complexity of the problem and to make coherent judgments about it. Thus, the $C R$ ratio is precisely the mathematical concept capable of synthesizing the competence that the decision-maker has to solve the specific problem at hand. The present communication proposes to objectively evaluate the students' degree of acquisition of the transversal competency critical thinking by deriving $C R$ from the comparsison matrices resulting from sustainability-based case studies.

\subsection{Evaluation activity}

The well-known learning pyramid suggests that the participatory learning activities, such as group discussion or practice, play an essential role in the education and learning process of students (Fig. 1). In particular, research shows that active learning strategies facilitate the acquisition of critical thinking skills $[24,25]$. To take advantage of both ideas, the evaluation procedure is proposed here as a participatory learning activity that shall promote, through its resolution by the students, the simultaneous acquisition of higher levels of this competency. 


\begin{tabular}{cll} 
& Lecture & $5 \%$ \\
Passive & Reading & $10 \%$ \\
\cline { 2 - 3 } Teaching & Audio-Visual & $20 \%$ \\
\cline { 2 - 3 } Participatory & Demonstration & $30 \%$ \\
\cline { 2 - 3 } Teaching & Practice & $50 \%$ \\
\cline { 2 - 3 } & Teaching Others & $90 \%$ \\
\hline
\end{tabular}

Figure 1. Average learning retention rates.

Thus, the evaluation process is proposed here to consist of several steps oriented towards active learning. Firstly, the case study is presented to the students. Here, the resolution of a particular, engineering-related case study has been proposed to the students of the Master's Degree in Planning and Management in Civil Engineering, offered at the UPV. Given that the profile of the student of this master's degree is that of a civil engineer or architect, the case study proposed is directly related to the ninth SDG (Design of Sustainable Infrastructures) and based on Navarro et al. [26]. According to [26], the sustainability of performance of a bridge design over a service life of 100 years can be quantified by means of 9 criteria covering the 3 dimensions of sustainability, namely economy, environment and society. The economic criteria considered in the study are the costs resulting from the construction of the bridge, and those derived from its maintenance along its life. Navarro et al. [26] consider 3 environmental criteria which are in line with life cycle impact assessment methodologies widely accepted by the scientific community, such as ReCiPe. Those criteria include the damage generated to human health, the damage to existing ecosystems, and the depletion of human resources. At last, 4 design criteria are considered that account for the social impacts derived from a design, namely the generation of employment; the increase of economic wealth of the region where the infrastructure is located as well as those that benefit from providing the required construction materials; the negative impacts on the users of the infrastructure resulting from maintenance, as maintenance activities can derive in travel delays or accidentality; and the impacts on the public opinion resulting from the aesthetics of the bridge and how maintenance operations might affect it, as well as from other externalities such as noise or dust generated by construction and maintenance.

Each of those criteria shall be explained in depth to students, so that they achieve to understand the complex relations that might exist between them when assessing the sustainability performance associated to a particular infrastructure such as a bridge. A debate activity is then encouraged so that they get to know different points of view regarding the same problem and help them build their own vision of the problem consistently. Through an online survey, students are then requested to compare the relevance that they believe that each of those criteria should have when it comes to choosing a particular design in sustainable terms. These comparisons are requested to be done in a pairwise manner, so that a comparison matrix can be extracted to serve as input for the AHP based procedure to obtain the associated Consistency Ratio.

\section{RESULTS}

The survey was conducted on 23 students of the Master's Degree. From the results of each individual survey it has been possible to obtain the consistency ratio of each student's answers (Fig. 2). It is observed that a wide range of Consistency Ratios has been obtained, ranging from very consistent results $(C R=0.064)$ to very poor surveys $(C R=0.570)$. 


\begin{tabular}{|c|c|}
\hline STUDENT & CR \\
\hline ST1 & 0.136 \\
ST2 & 0.103 \\
ST3 & 0.277 \\
ST4 & 0.063 \\
ST5 & 0.204 \\
ST6 & 0.064 \\
ST7 & 0.211 \\
ST8 & 0.261 \\
ST9 & 0.225 \\
ST10 & 0.464 \\
ST11 & 0.181 \\
ST12 & 0.421 \\
ST13 & 0.430 \\
ST14 & 0.103 \\
ST15 & 0.115 \\
ST16 & 0.401 \\
ST17 & 0.391 \\
ST18 & 0.127 \\
ST19 & 0.162 \\
ST20 & 0.159 \\
ST21 & 0.570 \\
ST22 & 0.570 \\
ST23 & 0.401 \\
\hline
\end{tabular}

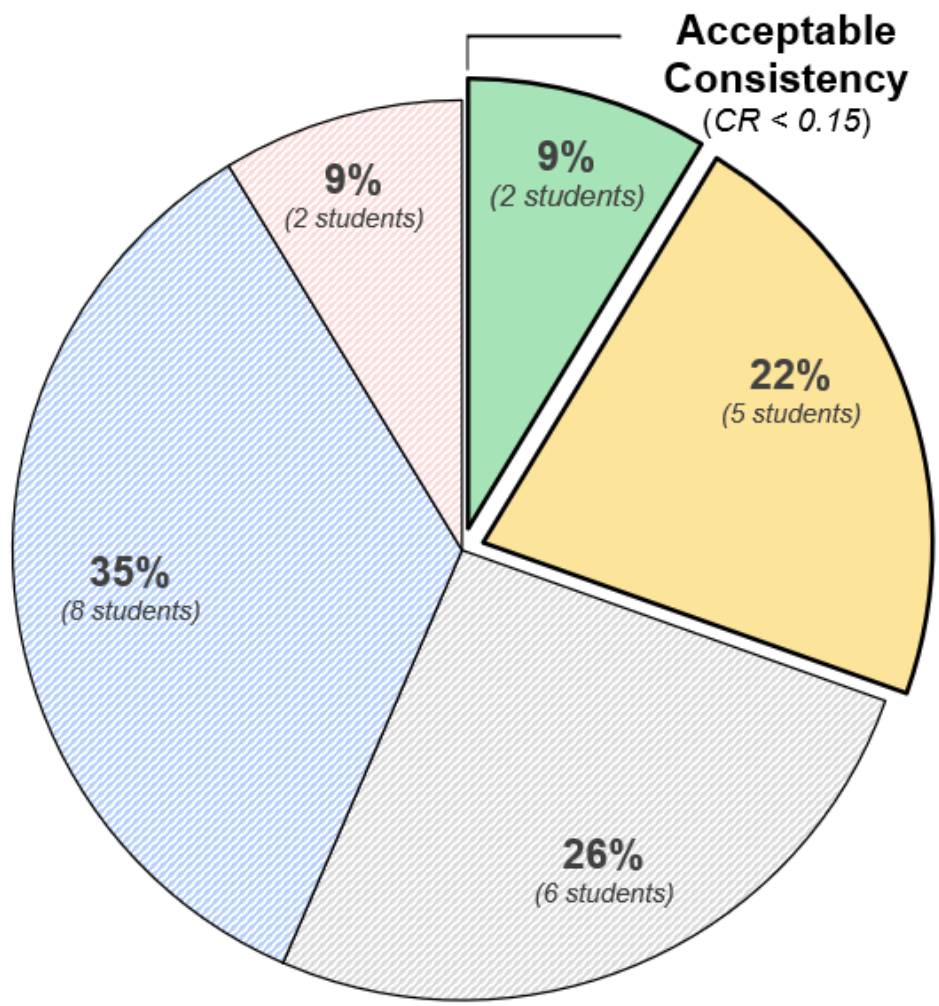

$\square \underline{\mathrm{CR}<0.10} \square \underline{0.1<\mathrm{CR}<0.15} \quad \square 0.15<\mathrm{CR}<0.25 \quad \square 0.25<\mathrm{CR}<0.5 \quad \square \mathrm{CR}>0.5$

Figure 2. Consistency Ratios (CR) obtained from surveys.

According to the AHP methodology, only a certain amount of inconsistency is acceptable for the results of the method to be considered valid. A similar approach is proposed here to aid the evaluation procedure. For an MCDM problem with 9 criteria, Saaty [23] suggests a limit value for $C R$ of $10 \%$. For the particular case presented here, it is observed that only 2 out of the 23 students have reached a consistency ratio below the $10 \%$ required by Saaty to validate the judgments of a decision matrix. However, this limit has been questioned on multiple occasions [27, 28] for not having a clear mathematical basis. In this work, and for the purpose of evaluating the critical thinking competency in the area of sustainability, we are going to assume that $C R$ values of up to $15 \%$ are consistent enough. This value is a target consistency, which will depend on the particular objectives of the course. So, from the ratio between the target consistency and the actual consistency derived from the survey, the level of achievement of the transversal competency critical thinking can be evaluated for each individual student objectively.

Thus, assuming a target consistency of $C R=0.15$, it is observed that $30 \%$ of the students have reached acceptable consistencies in their judgments. On the other hand, 10 out of the 23 students have obtained CR values above $25 \%$. Such high values indicate a rather considerable lack of consistency and reliability in their judgments, reflecting a lack of critical thinking in addressing an engineering problem from the perspective of sustainability.

\section{CONCLUSIONS}

The 2030 Agenda for sustainable development raises the need for professionals trained in the near future to acquire a set of transversal skills that will allow them to direct their professional practice towards a sustainable development of our society. Such need is particularly urgent in the engineering and architectural field, as the ninth SDG requires infrastructures to be sustainable by 2030. The present work proposes a methodology to detect the level of achievement of the transversal competency of critical thinking in any phase of the students' learning. For this purpose, an indirect and objective evaluation system is proposed here, based on the resolution of practical case studies. These case studies, customized for each particular course, aim to motivate students and promote their critical thinking and analytical skills applied to the sustainable design. 
The proposed tool allows to know, through the implicit coherence emitted by the students in their answers, to what extent the student has developed his capacity of critical thinking to face problems related to the sustainable design. The proposed evaluation system offers an objective map of how students perceive the new challenges coped by the recently established SDG, and allows us to know if it is necessary to modify the teaching strategy to fill the gaps that might be detected in their training after the analysis of the obtained results.

\section{ACKNOWLEDGEMENTS}

The authors acknowledge the financial support of the Spanish Ministry of Economy and Competitiveness, along with FEDER funding (Project: BIA2017-85098-R).

\section{REFERENCES}

[1] United Nations General Assembly, "Transforming our world: The 2030 Agenda for Sustainable Development”. A/RES/70/1 (21 October), 2015.

[2] C. Torres-Machí, A. Carrión and V. Yepes, E. Pellicer, "Employability of graduate students in construction management," Journal of Professional Issues in Engineering Education and Practice, vol. 139, no. 2, pp. 163-170, 2013. https://doi.org/10.1061/(ASCE)El.19435541.0000139

[3] V. Yepes, E. Pellicer and J.A. Ortega, "Designing a benchmark indicator for managerial competences in construction at the graduate level," Journal of Professional Issues in Engineering Education and Practice, vol. 138, no. 1, pp. 48-54, 2012. https://doi.org/10.1061/(ASCE)El.1943-5541.0000075

[4] T. Kestin, M. Van Den Belt, L. Denby, K. Ross, J. Thwaites and M. Hawkes, "Getting started with the SDGS in universities - A guide for universities, higher education institutions, and the academic sector," Sustainable Development Solutions Network (SDSN) Australia/Pacific, 2017.

[5] A.J. Sánchez-Garrido and V. Yepes, "Multi-criteria assessment of alternative sustainable structures for a self-promoted, single-family home," Journal of Cleaner Production, vol. 258, p. 120556, 2020. https://doi.org/10.1016/j.jclepro.2020.120556

[6] V. Yepes and J.R. Medina, "Land Use Tourism Models in Spanish Coastal Areas. A Case Study of the Valencia Region," Journal of Coastal Research, vol. 49, 83-88, 2005.

[7] T. García-Segura, V. Yepes and D.M. Frangopol, "Multi-Objective Design of Post-Tensioned Concrete Road Bridges Using Artificial Neural Networks," Structural and Multidisciplinary Optimization, vol. 56, no. 1. pp. 139-150, 2017. https://doi.org/10.1007/s00158-017-1653-0

[8] I.J. Navarro, J.V. Martí and V. Yepes, "Reliability-based maintenance optimization of corrosion preventive designs under a life cycle perspective," Environmental Impact Assessment Review, vol. 74, pp. 23-34, 2019. https://doi.org/10.1016/j.eiar.2018.10.001

[9] C. Torres-Machi, E. Pellicer, V. Yepes and A. Chamorro, "Towards a sustainable optimization of pavement maintenance programs under budgetary restrictions," Journal of Cleaner Production, vol. 148, pp. 90-102, 2017. https://doi.org/10.1016/j.jclepro.2017.01.100

[10] I. Payá-Zaforteza, V. Yepes, F. González-Vidosa and A. Hospitaler, "On the Weibull cost estimation of building frames designed by simulated annealing," Meccanica, vol. 45, no. 5, pp. 693-704, 2010. https://doi.org/10.1007/s11012-010-9285-0

[11] I.J. Navarro, V. Yepes and J.V. Martí, "Life cycle cost assessment of preventive strategies applied to prestressed concrete bridges exposed to chlorides," Sustainability, vol. 10, no. 3, p. 845, 2018. https://doi.org/10.3390/su10030845

[12] V. Penadés-Plà, J.V. Martí, T. García-Segura and V. Yepes, "Life-cycle assessment: A comparison between two optimal post-tensioned concrete box-girder road bridges," Sustainability, vol. 9, no. 10, p. 1864, 2017. https://doi.org/10.3390/su9101864

[13] I.J. Navarro, V. Yepes, J.V. Martí and F. González-Vidosa, "Life cycle impact assessment of corrosion preventive designs applied to prestressed concrete bridge decks," Journal of Cleaner Production, vol. 196, pp. 698-713, 2018. https://doi.org/10.1016/j.jclepro.2018.06.110 
[14] L.A. Sierra, E. Pellicer and V. Yepes, "Social sustainability in the life cycle of Chilean public infrastructure," Journal of Construction Engineering and Management, vol. 142, no. 5, p. 05015020, 2016. https://doi.org/10.1061/(ASCE)CO.1943-7862.0001099

[15] I.J. Navarro, V. Yepes and J.V. Martí, "Social life cycle assessment of concrete bridge decks exposed to aggressive environments," Environmental Impact Assessment Review, vol. 72, pp. 50-63, 2018. https://doi.org/10.1016/j.eiar.2018.05.003

[16] Z. Straková and I. Cimermanová, "Critical thinking development - A necessary step in Higher Education transformation towards sustainability," Sustainability, vol. 10, issue 10, p. 3366, 2018. https://doi.org/10.3390/su10103366

[17] M. Kallet, "Think smarter: Critical thinking to improve problem-solving and decision-making skills," New Jersey, Wiley, 2014.

[18] G. Cebrián and M. Junyent, "Competencies in Education for Sustainable Development: Exploring the Student Teachers' Views," Sustainability, vol. 7, no. 3, pp. 2768-2786, 2015. https://doi.org/10.3390/su7032768

[19] W. Lambrechts, I. Mulà, K. Ceulemans, I. Molderez and V. Gaeremynck, "The integration of competences for sustainable development in higher education: an analysis of bachelor programs in management," Journal of Cleaner Production, vol. 48, pp. 65-73, 2013. https://doi.org/10.1016/j.jclepro.2011.12.034

[20] M.L. Cruz, G. Saunders-Smits and P. Grone, "Evaluation of competency methods in engineering education: a systematic review," European Journal of Engineering Education, 2019. https://doi.org/10.1080/03043797.2019.1671810

[21] A.G. Ljungman and C. Silén, "Examination involving students as peer examiners," Assessment \& Evaluation in Higher Education, vol. 33, no. 3, pp. 289-300, 2008. https://doi.org/10.1080/02602930701293306

[22] K. Pond and O. Palermo, "Student Experiences of Peer Review Marking of Team Projects," International Journal of Management Education, vol. 6, no. 1, pp. 30-43, 2007. http://dx.doi.org/10.3794/ijme.62.190

[23] T. Saaty, "The Analytic Hierarchy Process," New York, McGraw-Hill, 1980.

[24] N. Michel, J.J. Cater and J. Varela, "Active versus passive teaching styles: an empirical study of student learning outcomes," Human Resource Development Quarterly, vol. 20, no. 4, pp. 397418, 2009. https://doi.org/10.1002/hrdq.20025

[25] S. Walker, "Active learning strategies to promote critical thinking," Journal of Athletic Training, vol. 38, no. 3, pp. 263-267, 2003.

[26] I.J. Navarro, V. Yepes and J.V. Martí, "Sustainability assessment of concrete bridge deck designs in coastal environments using neutrosophic criteria weights," Structure and Infrastructure Engineering, vol.16, no. 7, pp. 949-967, 2020. https://doi.org/10.1080/15732479.2019.1676791

[27] J. Franek and A. Kresta, "Judgement scales and consistency measure in AHP," Enterprise and the Competitive Environment 2014 Conference, Brno, Czech Republic, 6-7 March 2014. https://doi.org/10.1016/S2212-5671(14)00332-3

[28] J. Aguarón, M.T. Escobar, J.M. Moreno-Jiménez and A. Turón, "AHP-Group Decision Making Based on Consistency," Mathematics, vol. 7, no. 3, p. 242, 2019. https://doi.org/10.3390/math7030242 